\title{
As novelas exemplares de cervantes nas antologias brasileiras
}

\section{The exemplary novels by cervantes in the brazilian anthologies}

Célia Navarro FLORES ${ }^{1}$

(Universidade Federal de Sergipe)

\begin{abstract}
Resumo: Em 1613, o escritor espanhol Miguel de Cervantes (1547-1616) publicou um livro contendo uma série de doze contos sob o título Novelas ejemplares. Estes contos não obtiveram o mesmo êxito editorial que sua consagrada obra El ingenioso bidalgo Don Quijote de la Mancha, mas depois deste é a obra cervantina mais publicada internacionalmente. Este trabalho visa medir o sucesso (NITRINI, 1997) que os contos de Cervantes obtiveram no Brasil, a partir de um corpus de dez antologias brasileiras, publicadas de 1942 a 2001. Entretanto, mais do que apenas quantificar a frequência dos contos nessas antologias, decidimos, a partir da análise de seu peritexto (GENETTE, 2009), observar como os contos de Cervantes são classificados pelos antologistas, qual o público-alvo e, principalmente, quais as impressões que antologistas, tradutores e editores têm dessa obra cervantina.
\end{abstract}

PALAVRAS-CHAVE: Novelas exemplares. Cervantes. Peritexto. Sucesso. Antologias.

ABSTRACT: In 1613, the Spanish writer Miguel de Cervantes (1547-1616) published a book containing a series of twelve stories under the heading Novelas ejemplares. These stories had not gotten the same publishing success that its consecrated workmanship El ingenioso bidalgo Don Quijote de La Mancha, but after this book, the Novelas ejemplares is the Cervantes' workmanship more published internationally. This work aims at to measure the success (NITRINI, 1997) that the short stories of Cervantes had gotten in Brazil, from one corpus of ten Brazilian anthologies, published between 1942 and 2001. However, more than only quantify the frequency of the short stories in these anthologies, we decided, from the analysis of its peritext (GENETTE, 2009), to observe as the stories of Cervantes are classified by the anthologists, which the public-target and, mainly, which the impressions that anthologists, translators and publishers have of this Cervantes workmanship.

KEY WORDS: Exemplary novels. Cervantes. Peritext. Success. Anthologies.

Este ano comemoram-se os quatrocentos anos da publicação das Novelas exemplares do consagrado escritor espanhol Miguel de Cervantes. Mais conhecido internacionalmente por sua extensa obra narrativa, El ingenioso hidalgo Don Quijote de La Mancha, Cervantes destacou-se também como escritor de narrativas curtas, como as que compõem suas Novelas ejemplares, objeto desse trabalho. A edição príncipe dessa obra cervantina, de 1613, contém 12 contos, a saber: "La gitanilla", "El amante liberal", "Rinconete y Cortadillo", "La española inglesa", "El licenciado Vidriera", "La fuerza de la sangre", "El celoso estremeño", "La ilustre fregona", "Las dos doncellas", "La señora Cornelia", "El casamiento engañoso" e "Coloquio de los perros". Entretanto, em 1788, Isidoro Bosarte anuncia a descoberta de um manuscrito, compilado por Francisco Porras de la Cámara, contendo três novelas exemplares de Cervantes, uma delas, entretanto, "La tía fingida" não constava na edição príncipe (GARCÍA LÓPEZ, 2001, p. C). A autoria desse conto tem sido objeto de polêmica entre os cervantistas: alguns afirmam ser de fato de Cervantes, enquanto outros consideram essa autoria improvável. Estes últimos alegam, entre outros argumentos, que o tema desse conto - o engano levado a

${ }^{1}$ Doutora em Letras pela Universidade de São Paulo. Professora Adjunta da Universidade Federal de Sergipe. Email: navarroflores@globo.com.

(C) Revista Moara, n.41, jan.-jun. 2014, Estudos Literários. ISSN 2358-0658 (Impresso).

Programa de Pós-Graduação em Letras / Universidade Federal do Pará. Todos os direitos reservados. 
cabo por uma cafetina - não condiz com a proposta de Cervantes, que afirma no prólogo da obra que: "los requiebros amorosos que en algunas hallarás, son tan honestos y tan medidos con la razón y discurso cristiano, que no podrán mover a mal pensamiento al descuidado o cuidadoso que le leyere" (CERVANTES, 2001, p. 18). Praticamente, todos os contos são unidades independentes, exceto dois: "El casamiento engañoso" y "El Coloquio de los perros". Ao final do primeiro, o personagem Peralta se admira da história contada por Campuzano, o qual diz que se ele se admira dessa história o que dirá da história da conversa dos dois cachorros, a qual ele havia presenciado e posteriormente anotado em um "cartapacio". Peralta pede que Campuzano lhe leia a história, que no papel, intitula-se "Novela y coloquio que pasó entre Cipión y Berganza", mais conhecida do público atual como "Coloquio de los perros". Em outras palavras, o final do primeiro conto serve de enlace e introdução ao segundo.

Nossa intenção, neste trabalho, é sondar como esses contos escritos há quatrocentos anos, na Espanha, circularam nas antologias brasileiras no século $\mathrm{XX}^{3} \mathrm{e}$ princípios do XXI. Para levar a cabo essa empresa, inicialmente procedemos a um levantamento das antologias publicadas no Brasil, nas quais constava algum dos contos das Novelas Exemplares de Cervantes, em tradução ao português. Tal levantamento foi realizado a partir da consulta dos catálogos da Biblioteca Nacional, das bibliotecas universitárias (USP, UERJ, UFF) e das lojas virtuais de livros usados. Dada nossa dificuldade em ir às bibliotecas pessoalmente para ver de perto as obras, procuramos adquirir o maior número possível delas nas lojas de livros usados. Outra preocupação foi adquirir as edições mais antigas, preferencialmente, as primeiras. Embora tenhamos feito uma pesquisa exaustiva, sabemos que sempre existirão edições das quais não tivemos notícias, nem nos catálogos das bibliotecas, nem nas casas de livros usados. O corpus levantado corresponde a dez antologias, número que cremos ser representativo das obras desse gênero publicadas no período delimitado.

Este levantamento propiciou, entre outras coisas, verificar a recepção desses contos no Brasil, principalmente no que diz respeito a seu sucesso. Sandra Nitrini, ao resenhar o livro de Paul Van Tieghen, traz-nos a seguinte definição do termo "sucesso": "Sucesso é um conceito de ordem quantitativa: indica o número de edições, as traduções, adaptações, objetos que se inspiraram na obra e leitores que a leram" (NITRINI, 1997, p. 169). Portanto, a frequência com que determinados contos circularam nas antologias brasileiras nos indicará o grau de sucesso que esses contos obtiveram perante o público brasileiro.

Mais do que simplesmente fazer um levantamento quantitativo da frequência com que este ou aquele conto aparece nas antologias, buscaremos analisar elementos das edições que possam nos indicar, por exemplo, algum motivo especial para a escolha do conto pelo antologista. Os elementos aos quais nos referimos são os que compõem o peritexto editorial, assim definido por Genette (2009, p. 21), em seu livro Paratextos editoriais:

\begin{abstract}
Denomino peritexto editorial toda a zona do peritexto que se encontra sob responsabilidade direta e principal (mas não exclusiva) do editor, ou talvez, de maneira mais abstrata porém com maior exatidão, da edição, isto é, do fato de um livro ser editado, e eventualmente reeditado, e proposto ao público sob uma ou várias apresentações mais ou menos diferentes. A palavra 'zona' indica que o traço característico desse aspecto do paratexto é essencialmente espacial e temporal; tratase do peritexto mais exterior: a capa, a página de rosto e seus anexos; e da realização material do livro, cuja execução depende do impressor, mas cuja decisão é tomada pelo editor, em eventual conjunto com o autor: escolha do formato, do papel, da composição tipográfica etc.
\end{abstract}

\footnotetext{
${ }^{2}$ Os requebros amorosos que em algumas acharás, são tão honestos e tão medidos com a razão e o discurso cristão, que não poderão mover a mau pensamento, ao descuidado ou cuidadoso que as ler.

${ }^{3}$ Não encontramos menção a edições anteriores ao século XX.
} 
Dos elementos do peritexto elencados no livro de Genette, analisaremos mais detidamente: os títulos das antologias, os formatos, as capas, os títulos e, principalmente, os textos que acompanham os contos, como o prólogo, as abas etc. Desses textos, ressaltaremos os comentários que os prologuistas fazem com relação ao conto publicado, o que pode nos sugerir o porquê da escolha daquele conto em detrimentos dos outros publicados nas Novelas exemplares. Os prólogos merecem destaques, pois, neles, muitas vezes os prologuistas expressam, de maneira crítica, suas opiniões sobre os contos que compões suas antologias, o que colabora para que determinemos o horizonte de expectativa da obra. Estamos utilizando aqui a palavra "prólogo", mas como veremos, este texto inicial, em algumas edições traz o título de "nota preliminar", "prefácio" e outros. Em muitas das antologias encontradas, há, além do prefácio, um texto que antecede cada um dos contos, os quais também serão motivo de análise.

Uma vez que nossa área de pesquisa é a Literatura Espanhola e Hispano-americana, pareceu-nos interessante destacar o nome de outros escritores do mundo hispânico que aparecem em algumas antologias. Esse procedimento colaborará para que averiguemos quais contistas hispânicos tiveram maior penetração no mercado editorial brasileiro e, cremos, poderá contribuir para que outros pesquisadores possam levar a cabo o estudo de recepção de determinados escritores espanhóis.

Este trabalho é um desdobramento de uma pesquisa anterior, na qual buscamos mostrar o sucesso das Novelas exemplares em edições brasileiras. Nessa pesquisa descobrimos que em determinado momento, o conto "La tía fingida" - que, como vimos, não é considerado de autoria de Cervantes - aparece em uma edição brasileira das Novelas exemplares, isto, seguramente por influência das antologias publicadas à época, nas quais, como veremos, esse conto apareceu com frequência. Nesse sentido, pudemos observar a força que têm as antologias no processo de recepção. Como observa Guillén, o antologista - essa figura que existe nas mais diversas culturas e civilizações é - um superleitor, que tem o poder de dirigir nossa leitura, modificando o horizonte de expectativas da obra lida:

\footnotetext{
Veamos la antología ¿A qué categoría - genérica, formal, temática- puede adscribirse. La antología es una forma colectiva intratextual que supone la reescritura o reelaboración, por parte de un lector, de textos ya existentes mediante su inserción en conjuntos nuevos. La lectura es su arranque y su destino, puesto que el autor es un lector que se arroga la facultad de dirigir la lectura de los demás, interviniendo en la recepción de múltiples poetas, modificando el horizonte de expectativas de sus contemporáneos. Escritor de segundo grado, el antólogo es un superlector de primerísimo rango. Pues bien, sin duda el antólogo desempeña una función indispensable, puesto que topamos con él en las más diversas culturas y civilizaciones, sin excluir las primitivas o exclusivamente orales. Es más, difícil es concebir la existencia de una cultura sin cánones, autoridades e instrumentos de selección ${ }^{4}$. (GUILLÉN, 2005, 375).
}

Com o intuito de resumir e de visualizar mais facilmente o percurso dos contos cervantinos nas antologias, anexamos um quadro ao final deste texto. Finalmente, esclarecemos que, por ser este um estudo diacrônico, obedeceremos à ordem cronológica das edições.

\footnotetext{
${ }^{4}$ Vejamos a antologia. A que categoria - genérica, formal, temática - pode adscrever-se? A antologia é uma forma coletiva, intratextual que supõe a escritura ou reelaboração, por parte de um leitor, de textos já existentes mediante sua inserção em conjuntos novos. A leitura é seu arranque e seu destino, posto que o autor é um leitor, que se arroga a faculdade de dirigir a leitura dos demais, intervindo na recepção de múltiplos poetas, modificando o horizonte de expectativas de seus contemporâneos. Escritor de segundo grau, o antólogo é um superleitor de primeiríssima classe. Pois bem, sem dúvida o antólogo desempenha uma função indispensável, posto que topamos com ele nas mais diversas culturas e civilizações, sem excluir as primitivas ou as exclusivamente orais. Mais que isso, difícil é conceber a existência de uma cultura sem cânones, autoridades e instrumentos de seleção.
} 
Em 1942, encontramos uma primeira antologia, intitulada As obras primas do conto universal, publicada pela Livraria Martins Editora, na qual figura um dos contos das Novelas exemplares de Cervantes. É o volume VI da coleção "A marcha do espírito", com introdução, notas, compilações e traduções de Almiro Rolmes Barbosa e Edgard Cavalheiro. O livro contém ainda retratos dos autores dos contos, desenhados por Urban. Trata-se de uma edição bem cuidada, com capa dura marrom, na qual temos o título da coleção apenas na lombada. $O$ livro, com 381 páginas, traz 21 contos de autores da literatura universal; cada conto é precedido de uma pequena biografia do autor e um retrato de página inteira, exceto o primeiro conto, que é de autor anônimo. Na introdução, os organizadores tecem comentários sobre a arte de narrar e sobre a história do conto, mencionando o nome de Cervantes:

Da Itália, a "novella" espalhou-se pela Europa toda. Na Alemanha, na Espanha, na Bohêmia [sic], tornou-se a forma mais popular de se narrar os acontecimentos, tendo grande aceitação, principalmente, na terra do Cid Campeador, florescendo nas "Novelas exemplares" de Cervantes, ainda hoje consideradas modelo no gênero. (BARBOSA, CAVALHEIRO, 1944, p. 10)

Aqui, os antologistas apontam as Novelas exemplares como um "modelo no gênero". De fato, a crítica cervantina considera esses contos como precursores da narrativa curta moderna.

Os autores estabelecem os critérios de seleção dos contos: que eles fossem interessantes (BARBOSA, CAVALHEIRO, 1994, p.13). Entretanto, ao terminar a seleção de contos, constataram que "os trabalhos escolhidos constituíam um pequeno, mas variado panorama do desenvolvimento do conto no último século, com trabalhos dos mais célebres escritores, dos mais diferentes estilos, línguas e tendências" (BARBOSA, CAVALHEIRO, 1994, p. 13). Os antologistas descartaram contos de autores de língua portuguesa e contemporâneos. Com relação aos contos selecionados, eles os classificaram em picarescos entre outros, o conto de Cervantes -, humorísticos, líricos, psicológicos e misteriosos. Buscaram também escolher os contos mais representativos de seus autores, segundo a introdução.

Na breve biografia de Cervantes que precede seu conto, os antologistas comentam as Novelas exemplares:

Cervantes é autor de um romance pastoral -"A Galatéia -, de algumas peças
teatrais e muitos poemas, além das "Novelas exemplares", muitas das quais
constituem legítimas obras-primas, como Novela de La Gitanila [sic]", "Novela da
Senhora Cornélia", "Novela do Ciumento", "Novela do Licenciado Vidreira",
"Novela do Casamento Enganoso", etc. O mesmo estilo pitoresco, a mesma graça
do livro imortal [Dom Quixote]. E a mesma profundeza na análise dos caracteres
humanos, a mesma percuciência na crítica aos costumes da época, a mesma
observação magistral dos pequenos (e grandes) ridículos desta humanidade. Páginas
de um gênio. Apesar da intenção moralizante do título, as "Novelas exemplares"
não visam qualquer objetivo religioso ou simplesmente moral. É verdade que
Cervantes nos previne dizendo que "no hay ninguna de que no se pueda sacar un
ejemplo provechoso". Mas, moralizantes ou não, o certo é que das suas produções,
são as únicas dignas de figurarem ao lado do D. Quixote. Já notaram mesmo que as
aventuras como as do Licenciado Vidreira poderiam ser enquadradas sem muito
esforço entre as aventuras de Quixote e Sancho. (BARBOSA, CAVALHEIRO,
1944, p. 105)

É interessante que os prologuistas colocam as Novelas exemplares no mesmo patamar do Quixote, diferentemente de outros comentadores da obra em questão, que as colocam em nível inferior àquele. Também acertam quando afirmam que os contos de Cervantes excedem a simples intenção moralizante. 
O conto escolhido por Barbosa e Cavalheiro é o "O casamento enganoso". Como vimos no início deste trabalho, na obra de Cervantes, este conto está intimamente relacionado ao conto seguinte, "El coloquio de los perros". O procedimento dos antologistas é o de excluir o final do conto "El casamiento engañoso", o qual introduz o conto seguinte. Portanto, podemos dizer que esse conto aparece mutilado nessa antologia.

Chamamos a atenção para o fato de que esse conto de Cervantes não figurava nas edições das Novelas exemplares anteriormente à publicação dessa antologia. Entretanto, a Livraria Martins lança, logo após essa antologia, em 1950, uma edição das Novelas exemplares que leva por título o nome de um dos contos de Cervantes, Cornélia - também em tradução de Edgard Cavalheiro -, na qual inclui "O casamento enganoso" também mutilado.

Em 1944, vamos encontrar o nome de Cervantes em uma antologia, composta por 45 contos, com 311 páginas, intitulada Os mais belos contos galantes dos mais famosos autores, publicada pela Editora Vecchi. A edição é bastante simples, sem prólogo nem ilustrações, com uma capa básica, na qual há apenas o título da antologia com a palavra "galantes" em destaque, e o nome da editora. $\mathrm{Na}$ quarta capa, veicula-se a propaganda de outra obra publicada pela editora Vecchi. O papel é de qualidade não muito boa. Tampouco consta o nome do responsável pela seleção de contos, o que nos leva a atribuir a seleção aos editores. Temos apenas um elenco de tradutores, a saber: Frederico dos Reys Coutinho, Líbero Rangel de Andrade, J. da Cunha Borges, Manuel R. da Silva, Alfredo Ferreira, J. Dubois Júnior e Gilberto Galvão.

Chamamos a atenção para a palavra "galante" do título, que a primeira vista pode nos dar a impressão que se trata de contos elegantes, refinados, corteses, porém a palavra "galante" possui outras acepções, as quais parecem corresponder melhor à intenção do prologuista, que são: "picante" e "malicioso", uma vez que constam entre os escritores selecionados, nomes como o de Boccaccio e do conde de Mirabeau.

O conto selecionado, que corresponde ao nome de Cervantes é "A falsa tia" ["La tía fingida"]. Como vimos, esse conto não é reconhecidamente de autoria de Cervantes, justamente porque seu conteúdo erótico não corresponderia à intenção "honesta" dos contos que compõem as Novelas exemplares. Entretanto, o conto se encaixa perfeitamente no tema da antologia, que seriam os contos "galantes", ou seja, "picantes". O tradutor do conto é Líbero Rangel de Andrade, conforme indicado no índice do livro.

A antologia traz outros nomes do mundo hispânico: Juan Valera ( $O$ último pecado), Blasco Ibáñez (O milagre de Santo Antonio), Aranáz Castellanos ("Noite de ano", de amor) e Joaquin Belda (Monsier Carreau, costureiro).

Se na primeira antologia o conto de Cervantes estava mutilado, para esta antologia selecionou-se um conto que nem sabemos se, de fato, é de Cervantes.

Em 1945, a Editora José Olympio lança o primeiro volume de Mar de histórias. Antologia do conto mundial: das origens ao século XVIII, elaborado por dois grandes nomes: Aurélio Buarque de Holanda Ferreira e Paulo Rónai. Infelizmente, não tivemos acesso ainda à primeira edição, porém consultamos a edição de 1979, da Editora Nova Fronteira. O que sabemos da primeira edição é que ela contém 348 páginas, dez ilustrações fora do texto e que o conto de Cervantes publicado é o "Rinconete e Cortadillo" ["Rinconete y Cortadillo"].

$\mathrm{Na}$ edição consultada, há um prefácio no qual os autores discorrem sobre a história dos relatos breves desde suas origens. Nesse texto comental a originalidade dos contos de Cervantes e Quevedo:

Até meados do século XVIII são gerais as feições do conto europeu predominância do enredo, tom licencioso, desfecho surpreendente - , sendo mal perceptíveis as diferenças nacionais e individuais. Aparece originalidade nalgumas, poucas, personalidades excepcionais como um Cervantes ou um

Quevedo". (FERREIRA, RÓNAI, 1979, p. 7) 
Precedendo os contos, há textos sobre seus respectivos autores. O texto que precede o "Rinconete e Cortadillo" inicia com uma citação do prólogo das Novelas exemplares no qual Cervantes se descreve fisicamente; na sequência, temos uma breve biografia de Cervantes, na qual são citadas suas obras. Com relação às Novelas exemplares e o conto escolhido, Ferreira e Rónai tecem comentários extremamente pertinentes:

Logo abaixo de D. Quixote, as Novelas exemplares, julgada complemento indispensável dele para o leitor moderno, constituem a mais importante das produções cervantinas. Nelas encontrou Goethe "um tesouro de deleites e de ensinamentos". O nome "exemplares" provém (confissão do próprio autor) de se poder de cada uma delas tirar um exemplo proveitoso. E — ainda é ele quem diz —, "se por algum modo percebesse que a lição dessas novelas poderia induzir a quem as lesse a algum mau desejo ou pensamento, preferiria cortar a mão com que as escrevi a entregá-las ao público". Há nessas narrações grande variedade de aspectos: a maioria delas tem um fundo romântico - "A ciganinha", "O amante liberal", "A senhora Cornélia", "A espanhola inglesa", por exemplo; outras - "O casamento enganoso" e o "O estremenho ciumento" - são novelas de costumes; "O licenciado Vidriera" é o caso de uma loucura genial, como a de D. Quixote; "O colóquio dos cães" lembra os diálogos de Luciano; e "Rinconete e Cortadillo", escolhido para esta antologia, pertence ao gênero picaresco. É uma larga pintura, singularmente movimentada e viva, de certo meio de Sevilha do fim do século XVI - meio de malandros, de gatunos, de malfeitores, de mulheres suspeitas. Além dos dois tipos que dão nome à história, desfila por ela uma vasta galeria: o sr. Monopódio, Maniferro, Chiquenazque, Repolido, a Gananciosa, a Pipota... A descrição do ambiente é de um realismo da melhor espécie; na linguagem dos diálogos, tão numerosos, há excelentes flagrantes de fala popular e giriesca. "Rinconete e Cortadillo" agrupa-se, pois, entre as novelas realistas de Cervantes, preferidas geralmente às da outra classe, as de aventuras ou idealistas, - contra a opinião de Azorin, para quem "Cervantes é um gênio em permanente contacto com a realidade", mas só "atinge o máximo grau de sua arte quando sobre essa base intuitiva de realismo trata um assunto idealista e romântico". (FERREIRA, RÓNAI, 1979, p. 94-95)

Os prologuistas ainda têm o cuidado de citar, em nota de rodapé, o texto que deu origem à tradução, trata-se da edição da Espasa-Calpe, de 1941, organizada por Rodríguez Marín.

Chamamos a atenção para alguns elementos dos textos assinados pelos prologuistas: a referência à originalidade dos contos; o destaque dos aspectos picaresco e realista do conto escolhido e a citação de Azorín, aspectos que demonstram que os prologuistas tiveram uma preocupação em ler alguma crítica sobre a obra.

De 1956 é a antologia Titãs do Humorismo, volume 8 da coleção "Os titãs", editada pela Livraria "El Ateneo" do Brasil. A edição de luxo, em tamanho grande, contém 474 páginas e quarenta contos da literatura universal. Dentre autores como Pirandello, Maquiavel, Rabelais, Marck [sic]) Twain e Oscar Wilde, figura o nome de Cervantes. Os contos foram selecionados por Lázaro Liacho e todos foram traduzidos por M. C. de Oliveira, licenciado em Filosofia, segundo a página de rosto. Antes dessa página, temos a reprodução de um quadro de Honoré Daumier, intitulado "Tête de Pasquin", sob o qual há uma epígrafe: "Momo... Pierrot.... Arlequim... Iorick... Policinello... símbolos perenes do Humorismo humano! Uma máscara grotesca, forçando o sorriso, o riso, a gargalhada até... E atrás da máscara... a perpétua 'grimace' da vida!".

No Prólogo, os editores falam sobre a dificuldade em selecionar os contos, trazem algumas frases sobre o humorismo e expõem os critérios de seleção. 
[...] Não excluímos nenhum povo, estilo, época ou tipo de humor, porque todos eles são - acima das variantes superficiais - "humanos". De preferência selecionamos "obras" mais do que autores, porque um grande autor dramático por exemplo - pode, quando o caso se apresentar, desabrochar-se na mais intensa humorada (Yorick diante da caveira; Dom Quixote nas suas trágicas culminâncias). $[\cdots]$

Também não excluímos "espécie" alguma de humorismo; a gama humorística dessa Seleção abrange desde Rabelais (com suas brejeirices do mais grosso calibre) até Machado de Assis (finíssimo humorista, da mais decantada espirituosidade); desde as brincadeiras das tribus ( $\mathrm{sic}$ ) dos desertos (rememoradas nas Mil e uma noites) até as zombarias dos sertões, de saborosa pimenta nas Histórias de Alexandre. (EDITORES, 1956, p. 9)

Antes de cada conto, há um retrato de página inteira do autor e uma breve biografia. Os contos trazem notas explicativas no rodapé. $\mathrm{Na}$ biografia que precede o conto de Cervantes, as As novelas exemplares são citadas; entretanto, em nenhum momento diz-se se o conto em questão pertence ou não a esse livro. Talvez porque o conto selecionado seja, novamente, "La tía fingida", traduzido agora como "A tia fingida", relato que, como vimos, é de duvidosa autoria de Cervantes. Nesses textos encontramos um erro crasso, quando os editores afirmam que as Novelas exemplares foram publicadas em 1609, quando elas são de 1613.

Do mundo hispânico constam os nomes de Quevedo, Blasco Ibáñez e Mariano José de Lara, além de Cervantes.

Em 1958 e em 1962, são lançadas duas coletâneas diferentes das anteriores, pelo fato de não serem antologias de contos da literatura universal, como a primeira, ou temática como a de 1944 (contos picantes) ou a de 1956 (contos de humor). São antologias especificamente de contos de autores espanhóis. A primeira foi lançada pela Cultrix e a segunda pela Edigraf.

A antologia da Cultrix, de 1958, intitula-se Maravilhas do conto espanhol, a qual pertence à coleção "Maravilhas do conto universal" ${ }^{5}$. Trata-se de uma interessante coletânea de 21 contos de autores espanhóis, dentre eles: Cervantes, Alarcón, Pereda, Bécquer, Verdaguer, Pardo Bazán, Galdós, Clarim, Palacio Valdés, Unamuno, Blasco Ibáñez, Valle-Inclán, Baroja, Victor Catalá, Azorin, Zamacois, Concha Espina, José Francés, Ramón Gómez, Zunzunegui e Cela. O livro contém introdução e notas de Edgard Cavalheiro, organização Diaulas Riedel, seleção de Ángel Eugenio Echegaray, capa de Mogens Ove Österbye e desenhos de D. Nasi.

$\mathrm{Na}$ capa temos alguns símbolos da Espanha: a predominância das cores da bandeira espanhola (vermelho e amarelo), Dom Quixote e Sancho Pança (Sancho parece um garoto de boné e camiseta listrada) e um touro. Na quarta capa, temos uma "chamada" ao livro, assinada pela Editora. O primeiro conto da coletânea é uma das Novelas exemplares de Cervantes: "A força do sangue". Todos os contos são precedidos de um retrato de seu respectivo autor, realizado por D. Nasi, ao lado de uma pequena biografia. É curioso observar que na página de rosto consta "Traduções revistas por T. Booker Washington"; entretanto, não nos informa quem traduziu os contos. No caso do conto de Cervantes, comparamos esta tradução com a de uma edição das Novelas exemplares lançada pela Livraria Martins em 1950, e constatamos que se trata da mesma tradução, realizada por Edgard Cavalheiro, que, como vimos, é o responsável pela introdução e notas ao livro em questão, Maravilhas do conto espanhol.

$\mathrm{Na}$ "Introdução", Cavalheiro tece uma breve história do conto espanhol desde suas origens. Sobre as Novelas exemplares afirma que:

[...] [E]mbora intituladas "Novelas exemplares", a verdade é que Cervantes escreveu contos dos melhores, perfeitamente dentro das características exigidas pelo gênero. Mariano Baquero Goyanes anota que não é raro, no

${ }^{5}$ A Cultrix já havia lançado outras antologias, nessa coleção, de contos francês, inglês, norte-americano, alemão, russo, português e italiano. As próximas publicações anunciadas são de contos brasileiros e hispano-americanos. 
corpo dessas peças admiráveis, que ele fale em "conto", e não em "novela". [...] [É] com o autor de "Novelas ejemplares" que tem início esta parada de maravilhas da narrativa curta das letras espanholas. Não apenas por ser êle (sic) o nome mais conhecido entre nós, mas sim, também por ser, em verdade, a expressão máxima, aquele que mais alto elevou o gênero na sua terra. [...] (CAVALHEIRO, 1958, p. 11)

Neste fragmento, notamos primeiramente certa preocupação de Cavalheiro em buscar alguma teoria sobre a obra, ao citar Goyanes. Por outro lado, ele destaca o fato de Cervantes ser o autor mais conhecido pelo público brasileiro. Entretanto, se considerarmos a capa do livro, que traz Dom Quixote e Sancho, podemos afirmar que Cervantes era de fato conhecido, porém por meio do Quixote e não das Novelas exemplares.

$\mathrm{Na}$ breve biografia de Cervantes, que precede o conto, Cavalheiro elogia o Quixote e, posteriormente coloca as Novelas exemplares no mesmo patamar: "[...] Surge a obra incomparável, o livro que lhe garantiria a imortalidade - 'El Ingenioso Hidalgo Don Quijote de La Mancha"" e, mais adiante afirma que nas Novelas exemplares "encontramos o mesmo estilo, o mesmo pitoresco, a mesma graça do livro imortal".

A antologia da Edigraf, por sua vez, de 1962, cujo título é Contos Espanhóis, faz parte da coleção "Primores do conto universal". Trata-se de um livro mais elegante que a antologia da Cultrix: em papel de boa qualidade, a capa dura, na cor verde, traz apenas a figura de um toureiro, em relevo. Na lombada, há um ornato, o título da coleção "Primores do conto universal" e em letras maiores o título da antologia Contos espanhóis, todos em tinta dourada, além da figura de um toureiro em tinta branca.

A obra contém quinze contos - selecionados e organizados pelo Prof. Jacob Penteado - dos seguintes autores, conforme o índice: Dom Juan Manuel, Cervantes, Quevedo, Trueba, Alarcón, Pereda, Echegaray, Bécquer, Leopoldo Alas, Jacinto Otavio Picón, Palacio Valdés, Unamuno, Valle-Inglán ${ }^{6}$ [sic], Gabriel Miró, Pérez Ayala. Como podemos observar, vários autores da antologia de 1958 comparecem nessa edição, entretanto, em apenas um caso reproduz-se um conto da antologia anterior: o texto de Clarim. Dá-nos a impressão que o antologista conhecia a coletânea da Cultrix e, propositalmente, evitou colocar os mesmos contos. Não há nenhum indicativo do nome do tradutor. O livro traz um texto inicial intitulado "O conto espanhol" e todos os contos são precedidos de uma biografia de seu respectivo autor.

Chamou-nos a atenção o fato de que o conto selecionado de Dom Juan Manuel não seja uma tradução do original, mas uma tradução da versão realizada por Borges, intitulada "O bruxo postergado". Inclusive, mantém-se o título do conto de Borges, ignorando-se o título do conto de Dom Juan Manuel. Entretanto, ao final da biografia de Dom Juan Manuel, o antologista explica que o conto foi extraído do livro de Borges.

A novela de Cervantes selecionada por Penteado intitula-se "O estremenho ciumento". É curioso que este conto apareça já na primeira edição das Novelas exemplares publicada no Brasil em 1921 e só nos anos 60 ele compareça em antologias.

O texto que precede os contos, intitulado, como dissemos, "O conto espanhol", não está assinado, porém cremos ser de autoria de Penteado, quem selecionou os contos e organizou a edição. Nesse texto, o autor discorre brevemente sobre o conto espanhol. Sobre o conto de Cervantes, o antologista comenta: "em seu [de Cervantes] maravilhoso $O$ estremenho ciumento, retrato fiel de uma época cheia de preconceitos, como sempre foi a velha Espanha [...]" (PENTEADO, 1962, p. 11). Também nessa edição todos os contos são precedidos de uma pequena biografia do autor. Na biografia de Cervantes, por sua vez, encontramos apenas um comentário sobre Novelas exemplares, quando a autor afirma que o livro é uma "seleta de

${ }^{6} \mathrm{Na}$ página correspondente ao conto, o nome está grafado corretamente. 
contos de uma grande finura de observação" (PENTEADO, 1962, p. 20). Ao final da biografia, o antologista informa que "a interessante obra que se segue, $O$ estremenho ciumento, pertence às Novelas exemplares" (PENTEADO, 1962, p. 20).

Essa edição nos chamou a atenção pela qualidade do material físico com que foi confeccionada, porém deixou a desejar com relação a dois aspectos: o primeiro, o fato de não conter o nome do tradutor dos contos e o segundo, a escassez de informações sobre as Novelas exemplares e sobre os critérios de seleção dos contos.

A edição que descreveremos agora, intitulada Contos de alcova, infelizmente, não traz a data de sua publicação. Entretanto, encontramos uma referência ao mesmo livro, porém publicado por outra editora (Victor), em 1960. A que temos em mãos é a editora paulista $O$ Livreiro. A capa, de fato, parece ser dos anos 60. Nela, temos o desenho do formato de uma fechadura sobre um fundo negro e, no centro da fechadura, uma mulher sentada em uma cama, arquétipo da loura fatal, bastante maquiada, unhas vermelhas, abaixando a alça de uma exígua camisola e olhando sensualmente para um homem, do qual vemos apenas a mão e o punho da camisa. A mulher em questão lembra-nos a atriz norte-americana Marilyn Monroe, inclusive por ter uma pinta no rosto, como tinha a referida atriz. O título está em letras grandes na parte superior da capa e, na lombada, escrito em branco e vermelho. No lado esquerdo, em letras azuis pequenas, temos os nomes de alguns autores.

São 16 contos, selecionados por Yves Idílio, entre eles o de Cervantes, "Um casamento singular" [El casamiento engañoso]. Não sabemos se Idílio é o tradutor também ou apenas o organizador. No breve prefácio, Yves Idilio diz que o livro é "De contos de amor, sexo e romance..." (IDÍlLIO, s/d, p. 5), sua intenção é "fazer o leitor passar uns momentos agradáveis, revendo nos contos dos mestres, algumas de suas próprias aventuras, e aprofundálo nos seus parcos, - ou quiçá, profundos - conhecimentos sobre tão interessante tema..." (IDILIO, s/d, p. 5). Os autores selecionados são de diversos países, inclusive Brasil (Humberto de Campos) e Portugal (Eça de Queiroz e Miguel Torga). Entre os autores, constam os de língua hispânica: Cervantes e os chilenos Luis Orrego Luco e Mariano Latorre.

Dá-nos a impressão de que o livro é do mesmo gênero dos "contos galantes"; entretanto, o responsável pela edição coloca uma capa chamativa, para não dizer "apelativa" e o título "alcova" em vez de "galantes", que representa muito melhor a intenção picante dos contos. Com relação ao conto de Cervantes, novamente nos deparamos com "El casamiento engañoso" traduzido aqui por "Um casamento singular" e, obviamente sem a parte final que o enlaça com "El coloquio de los perros".

Em 1964, a Tecnoprint lança uma coletânea em formato de livro de bolso. Trata-se da obra O livro de bolso dos contos galantes, a qual nada mais é que uma reedição de Os mais belos contos galantes (Vecchi, 1944). Embora o texto seja o mesmo, decidimos incluir essa edição também, porque, por ser outra editora, o peritexto é bastante diferente do da edição da Vecchi. Em formato menor e com letras bem miúdas, o livro é o número 436 da coleção "Edições de ouro". Na terceira capa, temos uma tabela de classificação dos livros, de acordo com o preço: selo de ouro, medalha de outro, estrela de ouro, copa de outro e coroa de ouro. O selo da referida edição é "copa de ouro", o que nos indica que não se tratava das menos dispendiosas.

Comparando-se essa obra com a da Editora Vecchi, notamos que a Tecnoprint acrescentou uma vinheta na parte superior de alguns contos com uma cena representativa do conto ilustrado; os desenhos são do ilustrador Edmundo Rodrigues. O conto de Cervantes é o mesmo, "A tia falsa", traduzido por Líbero Rangel de Almeida. Na vinheta correspondente a esse conto, há três personagens vestidas à antiga: um cavalheiro, uma senhora e uma jovem trata-se dos protagonistas do conto -; no plano de fundo, temos uma espécie de coluna jônica e uma janela triangular, similar a um vitral, prováveis alusões à cidade onde se desenvolve a trama: Salamanca. Curiosamente, na capa, reproduz-se a vinheta referente ao conto Monsieur 
Carreau, costureiro, de Joaquin Belda, autor bem menos conhecido do público brasileiro que Cervantes.

Assim como a edição da Vecchi, o livro da Tecnoprint não traz nenhum prólogo, nem biografias, nem textos introdutórios aos contos, o que obviamente dificulta apurar qualquer tipo de opinião ou interpretação por parte dos editores.

De $1983^{7}$ é a antologia da Editora Ática, volume 11- Contos Universais, da série "Para gostar de ler". O livro, editado por Fernando Paixão, traz treze contos, selecionados por José Paulo Paes, de sete importantes autores: Tchekhov, Poe, Kafka, Maupassant, Jack London, Cervantes e Voltaire. O livro é amplamente ilustrado. A capa, de autoria de Ary A. Normanha, é bastante colorida e traz uma cena do conto "A mulher do farmacêutico", de Tchekhov: o cachorro latindo, a lua "encabulada", os dois visitantes da farmácia e ao fundo uma casa; há ainda uma espécie de selo com a silueta de um homem tomando remédio e em volta o nome do farmacêutico do conto "Tchornomordik" e a expressão: "gotas do rei da Dinamarca". Todos esses elementos pertencem ao referido conto de Tchekhov. É curioso que esse desenho não figura dentro da obra, mas sim apenas na capa.

Excetuando-se Cervantes, o livro contém dois contos de cada autor. Precedendo os contos, há uma pequena biografia do autor com uma ilustração, em um total de 7 ilustrações, além das ilustrações da primeira e da quarta capas. As biografias, por sua vez são precedidas de um retrato do respectivo autor. Na quarta capa, realizada de Jayme Leão, temos os retratos de todos os autores, seus nomes e a frase: "A condição humana mostrada nos mais diferentes aspectos por sete grandes escritores de todos os tempos em contos célebres da literatura universal". Apenas a primeira e a quarta capa são coloridas; as demais ilustrações são em preto e branco.

O conto de Cervantes que compõe a obrinha é "O casamento enganoso", traduzido por Mustafa Yazbek e sem a parte final, que serve de enlace ao conto "El colóquio de los perros". Obviamente porque este conto não faz parte desta antologia. Há um brevíssimo texto inicial (apenas quatro parágrafos), intitulado "Histórias do mundo inteiro"; em seu último parágrafo, temos uma pista da temática que une os contos, que seria a "condição humana": "Todas as histórias, embora distintas entre si, são igualmente fascinantes e atuais, pois falam, cada uma à sua maneira, de um tema que tocará ao leitor: a própria condição humana".

No texto que precede o conto de Cervantes, intitulado "O riso que leva à reflexão", após uma sucinta biografia do autor, há o seguinte comentário sobre suas obras:

\footnotetext{
Das obras de Miguel de Cervantes, destacam-se indiscutivelmente, seus textos em prosa, como por exemplo o volume Novelas exemplares, narrativas de ampla variedade temática, que vão do romântico ao picaresco e entre os quais está "O casamento enganoso", o texto que você vai ler. Mas a realização máxima de Cervantes é, sem dúvida, o célebre D. Quixote, considerado o marco inicial do romance moderno. Nessa que é uma das mais importantes obras da literatura universal de todos os tempos encontram-se pelo menos dois personagens - o cavaleiro D. Quixote e seu escudeiro Sancho Pança -, que hoje estão definitivamente incorporados ao patrimônio da humanidade. (PAIXÃO, 1988, p. 92-93).
}

O autor do texto efetivamente coloca o Quixote em um patamar superior às Novelas exemplares.

$\mathrm{Na}$ figura que ilustra esse texto temos Cervantes com um bico de pena enorme, no ombro, como se fosse uma lança, sentado sobre um cavalinho de madeira, de balanço, com uma expressão triste no rosto.

\footnotetext{
${ }^{7}$ A edição que temos em mãos é a de 1988.
} 
A capa colorida, com personagens que nos lembram histórias em quadrinhos, as ilustrações divertidas como a que acabamos de descrever e outras, os textos exíguos da introdução e das biografias são elementos que nos indicam que se trata de uma obra para o público infanto-juvenil.

Em $2001^{8}$, a Ediouro publica, em formato grande, com 546 páginas, uma bela edição intitulada Os 100 melhores contos de bumor da Literatura universal, com seleção, introdução, tradução e notas de Flávio Moreira da Costa. Outros tradutores participaram da edição, dentre eles constam nomes conhecidos como Mário Quintana, Millôr Fernandes, Aurélio Buarque de Holanda, Ruy Castro e outros. Entretanto, o conto de Cervantes escolhido para essa edição foi traduzido pelo próprio Flávio Moreira da Costa. Trata-se de novamente do conto "O casamento enganoso", sem sua parte final.

Embora seja uma edição de ótima qualidade, não é capa dura e nem traz qualquer ilustração. Por suas 539 páginas, desfilam autores desde a Antiguidade Clássica (Homero) até a contemporaneidade (João Ubaldo Ribeiro). Do mundo hispânico, temos alguns autores: Quevedo, Emilia Pardo Bazán, Felisberto Hernández, Cortázar e Augusto Monterroso.

$\mathrm{Na}$ "Introdução" - que tem como subtítulo "A sindrome de Akaki Akakiévich e os humores" - Costa (2001, p. 13-15) discorre sobre o humor e comenta algumas dificuldades na realização do projeto da antologia. $\mathrm{O}$ autor não faz nenhuma referência ao nome de Cervantes na introdução. Todos os contos são precedidos de um breve texto. No caso de "O casamento enganoso", Costa (2001, p.77) comenta que Cervantes é o pai do gênero romance, pois escreveu o Quixote, "o livro mais famoso depois da Bíblia e até hoje a obra mais original e humorística criada pelo engenho humano". "O casamento enganoso", por sua vez, "é um ótimo exemplo de comédia de costumes da época" (COSTA, 2001), porém Costa não diz que "O casamento enganoso" é uma das Novelas exemplares. Ao final do livro, há uma extensa bibliografia.

Dos 12 contos escritos por Cervantes em 1613, sob o título Novelas exemplares, apenas quatro compareceram nas antologias brasileiras: "El casamiento engañoso" (1942, 1960, 1983 e 2001), "Rinconete y Cortadillo" (1945), "La fuerza de la sangre" (1958) e "El celoso estremeño" (1962). "El casamiento engañoso" foi o conto publicado com maior frequência: quatro vezes em dez edições; em todas as edições, o conto aparece mutilado, ou seja, sem sua parte final, a qual enlaçaria com o conto seguinte. É possível que a frequência com que esse conto aparece esteja relacionada ao fato de ele ser o mais curto da obra de Cervantes, justamente porque ele continua no conto consecutivo. Agregamos a isso o fato de ele ser cortado pelos editores, tornando-o ainda mais breve.

"Rinconete e Cortadillo", "La fuerza de la sangre" e "El estremeño celoso" aparecem apenas uma vez cada. Curiosamente, "La tía fingida" (1944, 1956, 1964), cuja autoria nem sequer sabemos se realmente é de Cervantes, comparece nada menos que em três diferentes edições. Resumindo, as duas obras que obtiveram mais sucesso no Brasil, pois frequentaram maior número de edições são: o mutilado "El casamiento engañoso" e o de autoria duvidosa "La tía fingida".

As antologias vistas podem ser agrupadas em quatro grandes temáticas:

1) contos universais: As obras primas do conto universal (1942) da editora Martins, Mar de história: antologia do conto mundial (1945) da José Olympio, e Contos universais (1983) da Ática;

2) contos espanhóis: Maravilhas do conto espanhol (1958) da Cultrix, e Contos Espanhóis (1962) da Edigraf;

3) contos de humor: Titãs do Humorismo (1956) da editora El Ateneo e Os 100 melhores contos de bumor da literatura universal (2001) da Ediouro.

\footnotetext{
${ }^{8}$ Embora a edição consultada seja a quarta edição de 2001, cremos que a primeira também seja de 2001, pois no catálogo na Livraria Cultura consta que a primeira edição (esgotada) é de 2001 e não encontramos nenhuma referência a edições anteriores a esse ano. Também o texto introdutório é datado de 2001.
} 
4) contos picantes: Os mais belos contos galantes dos mais famosos autores (1944) da Vecchi, Contos de alcova (1960) da O Livreiro e O livro de bolso dos contos galantes (1964) da Tecnoprint.

É curioso observar que os contos que aparecem com maior frequência nem sempre são classificados sob o mesmo critério, ou seja, o mesmo conto aparece em antologias de diferentes temáticas: "El casamiento engañoso" faz parte de antologias de contos universais, de contos picantes e de contos de humor. "La tía fingida", por sua vez, tanto aparece em contos picantes quanto em contos de humor. Curiosamente, dos três contos publicados apenas uma vez, dois são em antologias específicas de escritores espanhóis: "La fuerza de la sangre" e "El celoso estremeño".

Embora, em geral, as antologias tenham sido publicadas visando um público mais amplo, a edição da Ática (1983), Contos universais, da coleção "Para gostar de ler" tem como objetivo alcançar um público mais específico, o infanto-juvenil. Por outro lado, os contos, que aqui denominamos "picantes" são dirigidos a um público adulto, como bem demonstra a capa dos Contos de alcova, da editora O livreiro, de 1960.

Com relação aos elementos textuais do peritexto, em particular os prólogos e os textos que precedem os contos, podemos dizer que alguns autores, como vimos, equiparam as Novelas exemplares ao Quixote, como Barbosa e Cavalheiro - que afirmam que As novelas exemplares "são as únicas dignas de figurarem ao lado do D. Quixote" (BARBOSA, CAVALHEIRO, 1942, p. 105); outros creem que elas estão em um nível inferior ao Quixote, como o editor Fernando Paixão, que afirma que "a realização máxima de Cervantes é, sem dúvida, o célebre D. Quixote" (PAIXÃO, 1988, p. 92-93) ou Ferreira e Rónai para quem as Novelas exemplares seriam um complemento do Quixote: "logo abaixo de D. Quixote, as Novelas exemplares, julgada complemento indispensável dele para o leitor moderno".

Em mais de um texto, vimos como seus autores reconhecem que as Novelas exemplares são um marco na história do relato curto: na introdução à edição de 1958, o autor reconhece que Cervantes foi o escritor "que mais alto elevou o gênero em sua terra" (CAVALHEIRO, 1958, p. 11) e Barbosa e Cavalheiro afirmam que as Novelas exemplares são "ainda hoje, consideradas modelo no gênero" (BARBOSA, CAVALHEIRO, 1944, p. 10) e Ferreira e Rónai apontam a originalidade nos contos de Cervantes, comparando-os a seus predecessores e afirmando que "[a]parece originalidade nalgumas, poucas, personalidades excepcionais como um Cervantes ou um Quevedo".

Chamamos atenção ainda para o fato de que a maior parte dos contos que comparecem nas antologias tem um viés picaresco, entre eles: "Rinconete y Cortadillo", "A tía fingida" e "El casamiento engañoso". Em "El celoso estremeño", há um personagem, Loaysa, que, embora não seja exatamente um pícaro, lança mão de artimanhas para seduzir a casada Leonora.

Cremos que, a partir do corpus levantado e da análise do peritexto das edições, foi possível mostrar, neste breve trabalho, como os contos de Cervantes ocuparam seus lugares nas antologias brasileiras no período delimitado e quais os contos que obtiveram maior sucesso em terras brasileiras, deleitando os leitores que gostam de uma boa história.

\section{REFERÊNCIAS}

BARBOSA, A. R.; CAVALHEIRO, E. As obras-primas do Conto Universal. São Paulo: Livraria Martins, 1942.

Catálogo da Fundação Biblioteca Nacional. Disponivel em:

<http://www.bn.br/portal/pesquisa/obrasgerais.htm> Acesso em: 21 set. 2012. 
Catálogo da Biblioteca da Faculdade de Filosofia, Letras e Ciências Humanas, da USP. Disponivel em: <http://dedalus.usp.br/F?RN=947578060>. Acesso em: 01/11/2012

CAVALHEIRO, E.; RIEDEL, D.; ECHEGARAY, A. E. Maravilhas do conto espanhol. São Paulo: Cultrix, 1958.

CAVALHEIRO, E. Introdução. In: Maravilhas do conto espanhol. São Paulo: Cultrix, 1958.

CERVANTES, M. A tia fingida. In Titãs do humorismo. Tradução de M. C. Oliveira. Rio de Janeiro: Livraria "El Ateneo" do Brasil, 1956. v. 8.

CERVANTES, M. A falsa tia. In: Os mais belos contos galantes dos mais famosos autores. Rio de Janeiro: Casa Editora Vecchi, 1944.

CERVANTES, M. A falsa tia. In: O livro de bolso dos contos galantes. Edições de ouro. Rio de Janeiro: Tecnoprint, 1964.

CERVANTES, M. O casamento enganoso. In: Para gostar de ler: Contos universais. São Paulo, Ática, 1988. v. 11.

CERVANTES, M. Novelas ejemplares. Barcelona: Crítica, 2001.

COSTA, F. M. Contos de humor. Rio de Janeiro: Agir, 2009.

COSTA, F. M. Introdução. A síndrome de Akaki Akakiévich e Cervantes. In: Os $\mathbf{1 0 0}$ melhores contos de humor da Literatura universal. 4. ed. Rio de Janeiro: Ediouro, 2001.

FEREIRA, A. B. H., RÓNAI, P. Rinconete e Cortadillo. In: Mar de histórias. Antologia do conto mundial II: do fim da Idade Média ao Romantismo. 2. ed. Rio de Janeiro: Nova Fronteira, 1979.

GARCÍA LÓPEZ, J. Prólogo. In: CERVANTES, M. Novelas ejemplares. Barcelona: Crítica, 2001.

GENETTE, Gérard. Paratextos editoriais. Tadução Álvaro Faleiros. Cotia, SP: Atelier editorial, 2009.

GUILLÉN, Claudio. Entre lo uno y lo diverso: Introducción a la Literatura Comparada (ayer y hoy). Barcelona: Tusquets, 2005.

IDILIO, Yves (Org.). Contos de alcova. São Paulo: O Livreiro, s/d.

NITRINI, S. Literatura comparada. São Paulo: EDUSP, 1997.

PAIXÃO, F. O riso que leva à reflexão. In: SABINO, F. (Org.) Para gostar de ler: contos universais. São Paulo, Ática, 1988. v. 11.

PENTEADO, Jacob (Org.). O conto espanhol. Contos Espanhóis. São Paulo: Edigraf, 1962. 
Traça. Disponivel em: http://www.traca.com.br/. Acesso em: 01/11/2012.

\section{Anexo}

\begin{tabular}{|l|l|l|l|l|}
\hline ANO & TÍTULO & TRADUÇÃO & EDITORA & NOVELAS \\
\hline 1942 & As obras primas do conto universal & $\begin{array}{l}\text { A. R. Barbosa e Edgard } \\
\text { Cavalheiro }\end{array}$ & $\begin{array}{l}\text { Livraria } \\
\text { Martins }\end{array}$ & O casamento enganoso \\
\hline 1944 & $\begin{array}{l}\text { Os mais belos contos galantes dos } \\
\text { mais famosos autores }\end{array}$ & $\begin{array}{l}\text { Líbero Rangel de } \\
\text { Andrade }\end{array}$ & Vecchi & A falsa tia \\
\hline 1945 & Mar de história & $\begin{array}{l}\text { Aurélio Buarque de } \\
\text { Holanda Ferreira e } \\
\text { Paulo Rónai }\end{array}$ & José Olympio & Rinconete e Cortadillo \\
\hline 1956 & Titãs do Humorismo & M. C. de Oliveira & $\begin{array}{l}\text { Livraria "El } \\
\text { Ateneo" do } \\
\text { Brasil }\end{array}$ & A tia fingida \\
\hline 1958 & Maravilhas do conto espanhol & Edgard Cavalheiro & Cultrix & A força do sangue \\
\hline 1960 & Contos de alcova & Yves Idílio & O Livreiro & Um casamento singular \\
\hline 1962 & Contos Espanhóis & (?) & Edigraf & O estremenho ciumento \\
\hline 1964 & O livro de bolso dos contos galantes & $\begin{array}{l}\text { Líbero Rangel de } \\
\text { Andrade }\end{array}$ & Tecnoprint & falsa tia \\
\hline 1983 & Contos universais & Mustafá Yazbek & Ática & O casamento enganoso \\
\hline 2001 & $\begin{array}{l}\text { Os 100 melhores contos de humor } \\
\text { da literatura universal }\end{array}$ & Flávio Moreira da Costa & Ediouro & O casamento enganoso \\
\hline
\end{tabular}

Recebido em 30/03/2013

Aprovado em 20/11/2013 